\section{AL-AZHAR}

Assiut Dental Journal
The Official Publication of The

Faculty of Dental medicine.

Al-Azhar Assiut Uniuersity.

AADJ, Vol. 2, No. 2, October (2019) - PP. 117:124

ISSn 2682-2822

\title{
Evaluation of Mandibular Foramen Variations Using Cone Beam Computed Tomography in Egyptian Population
}

\author{
Abo Zaid F*1, Hashim $\mathbf{R}^{2}$, Bakry ${ }^{3}$
}

Codex : 14/1910

Aadj@azhar.edu.eg

\section{KEYWORDS}

Mandibular foramen,

CBCT,

ramus,

mandibular notch,

tomography

1. Department of Oral Medicine, Periodontology, Diagnosis and Oral Radiology, Faculty of Dental Medicine, Al-Azhar University, Assiut, Egypt.

2. Department of Oral \& Maxillofacial Radiology , Assiut University , Egypt.

3. Department of Oral \& Maxillofacial Radiology, El Minia University, Egypt

* Corresponding Author e-mail: drfathey@azhar.edu.eg

\begin{abstract}
Aim: The present study designed to determine variations in mandibular foramen using CBCT in Egyptian population. Subjects and Method: 300 CBCT images were grouped according to sex, and symmetry between right and left sides into two groups. Group I: males\& female and group II: right \& left sides. Panoramic images were reconstructed from CBCT scans and evaluated using Blue sky software. The exact location of mandibular foramen at the two sides of the mandible was determined in relation to anterior border \& posterior border of ramus, mandibular base, and mandibular notch. The recorded data will be collected, tabulated and statistically analyzed by SPSS (Statistical Package for Social Sciences). Results: This study showed bilateral asymmetry between right and left sides, no significant difference between 2 sides of the mandible. There was high significant difference in the distance from MF to mandibular base between males and females. No significant difference in other parameters relative to vertical and horizontal dimensions of mandibular ramus. Conclusions: All parameters related to the position of mandibular foramen in vertical and horizontal dimensions of mandibular ramus (MF-MB), (MF-MN), (PB-MF), and (AB-MF) were symmetrical in the right and left sides. The distance from mandibular foramen to mandibular base (MF-MB) was greater in males than females.
\end{abstract}

\section{INTRODUCTION}

Various anatomical landmarks are being used as surgical marks for some surgical procedures ${ }^{(1)}$. These anatomical landmarks that are related with mandible are significant and can be damaged during oral and maxillofacial surgical procedures like mandibular osteotomies, orthognathic surgeries, mandibular trauma management, surgeries of benign and malignant lesions, implant surgeries, pre prosthetic surgeries and also nerve damage is possible during inferior mandibular nerve block ${ }^{(2)}$. The morphological knowledge of the mandibular foramen (MF) is of paramount importance during the dental procedures of the lower jaw. It is an anatomical landmark for inferior alveolar nerve block (IANB) and many surgical procedures like split sagittal osteotomies. Sagittal split 
osteotomies are done to reposition the mandible in prognatheism and retrogantheism ${ }^{(3)}$. MF transmits inferior alveolar nerve and vessels and inferior alveolar nerve block technique is commonly used in dental practice and also in reconstructive surgery ${ }_{-}^{(4)}$.

Detailed knowledge of variations in MF position in relation to relevant ramus anatomical land marks and of the relationship of the structures within the inferior alveolar neurovascular bundle enable the safe and effective delivery of IAN anesthesia. The location of the MF is also important when planning and conducting different mandibular ramus surgeries and other surgical treatments of dentofacial deformities, mandibular fractures and tumors ${ }^{(5)}$. The MF is often chosen as a reference point because of its stable relation with the base of the mandible in paleo-anthropological studies of the facial skeleton in different populations and for identification of the human remains ${ }^{(6)}$. Inferior alveolar nerve block is a necessary and fundamental local dental anesthetic procedure. The success of the procedure mainly depends on placing the needle tip close to the mandibular foramen. The inferior alveolar nerve block is one of the most used techniques of anesthesia, but in the same time one that can lead to failures caused by anatomical variations ${ }^{(7)}$.

Variations in the position of mandibular foramen and the presence of accessory mandibular foramina (AMF) are the main reasons accounting for the failure rates of this technique. During surgical procedures which involve the ramus of the mandible, it is important to be familiar with the incidence and the configuration of these foramina, since complications including unexpected bleeding, parathesia and traumatic neuroma are known to occur because of trauma to the accessory canals. Also the AMF can be the site for the spread of tumor cells following radiotherapy ${ }^{(8)}$.

Cone beam computed tomography is the most recent imaging technique in the maxillofacial imaging. The introduction of CBCT imaging has made a shift from a two - dimensional to a three - dimen- sional volumetric approach in maxillofacial imaging. The advent of 3-dimensional (3D) radiographic imaging with cone beam computed tomography (CBCT) has led to a multitude of clinical applications across all dental disciplines ${ }^{(9)}$. After an initial period of slow adoption and the emergence of other CBCT manufactures, this technology has become widely accepted ${ }^{(15)}$. In addition CBCT provides high resolution images in three dimensions with low radiation dose. Accuracy of the studies evaluates anatomic structures of the maxillofacial region progress with the development of CBCT systems ${ }^{(10)}$. Hence, this study will analyze the variations of mandibular foramen and the presence of accessory mandibular foramina in Egyptian persons regarding age and gender using CBCT imaging.

\section{METHODOLOGY}

This descriptive and analytical study was conducted on 300 cone beam computed tomography $(\mathrm{CBCT})$ images retrieved from the outpatient clinic of Oral \& Maxillofacial Radiology, faculty of Dentisty, Minia university, Oral Medicine, Periodontology, Diagnosis and Oral Radiology, faculty of Dental medicine, boys, Cairo, Al-zahar university and other private radiology centers. Cone beam computed tomography (CBCT) images were collected using convenience sampling. The sample size was calculated to be 300 .

\section{Inclusion criteria:}

- Cone beam computed tomography (CBCT) images of adult male and female patients.

- Cone beam computed tomography (CBCT) images of patients showing mandibular ramus and mandibular foramen.

\section{Exclusion criteria:}

- Children (primary \& mixed dentition) $<20$ year.

- Trauma, dysplasia, prior surgery of the mandibular ramus. 
- No visibility of the condyle or coronoid process of the mandible.

- Ramus pathology that causes alteration in the morphology of the ramus.

- Poor quality image due to motion artifacts.

Cone beam computed tomography (CBCT) images were grouped according to sex, age and symmetry between right and left sides of mandibular rami into the following groups:

\begin{tabular}{|l|l|}
\hline Group I: according to sex. & Group II: according to symmetry. \\
\hline IA: male & IIA: right side. \\
\hline IB: female & IIB: left side. \\
\hline
\end{tabular}

\section{Radiographic evaluation:}

Image analysis and panoramic reconstruction were done using Blue Sky Bio software. Panoramic images were reconstructed from CBCT scans with $12 \mathrm{~mm}$ thickness. All images were evaluated in standardized conditions e.g. room, light, and image size. The images were viewed on 14-inch LED (light emitting diode) monitor. No image enhancement was allowed.

The exact location of mandibular foramen at the two sides of the mandible was determined by measuring the following parameters:

\section{Anterior border-mandibular foramen (AB-MF):}

Distance from the mid-point of the anterior margin of mandibular foramen to the closest point in the anterior border of mandibular ramus.

\section{Posterior border - mandibular foramen (PB-MF):}

Distance from the mid-point of the posterior margin of mandibular foramen to the closest point in the posterior border of mandibular ramus.

\section{Mandibular foramen - mandibular notch (MF-MN):}

Distance from the most inferior point of the mandibular notch to inferior border of mandibular foramen.

\section{Mandibular foramen - mandibular base (MF-MB):}

Distance from the inferior border of mandibular foramen to mandibular base (tangent line to inferior border of mandible).

\section{Statistical analysis:}

The data were collected, tabulated and statistically analyzed.

\section{RESULTS}

300 CBCT images of adult patients were included in the present study, 148 (49.3\%) belonged to males and $152(50.7 \%)$ belonged to females. Cone beam computed tomography (CBCT) images were grouped according to sex and symmetry between right and left sides of_mandible.

Table (1): Illustrating mean $\pm S D$ of $M F-M B, M F$ $M N, P B-M F$, and $A B-M F$ in males and females.

\begin{tabular}{|c|c|c|c|}
\hline & $\begin{array}{c}\text { Females } \\
\text { Mean } \pm \text { SD }\end{array}$ & $\begin{array}{c}\text { Males } \\
\text { Mean } \pm \text { SD }\end{array}$ & P value \\
\hline MF-MB & $28.32 \pm 3.52$ & $30.59 \pm 5.16$ & $<0.0001^{* * *}$ \\
\hline MF-MN & $16.03 \pm 2.44$ & $15.68 \pm 3.38$ & 0.565 \\
\hline PB-MF & $12.04 \pm 1.85$ & $12.66 \pm 2.37$ & $0.01 *$ \\
\hline AB-MF & $16.83 \pm 2.58$ & $17.61 \pm 2.87$ & $0.024^{*}$ \\
\hline
\end{tabular}

Table (1) shows parameters related to the exact location of the mandibular foramen between males and females:

Mean of(MF-MB) in females was $28.32 \mathrm{~mm} \pm 3.52$ while, in males was $30.59 \mathrm{~mm} \pm 5.16$.

The MF-MB shows high significant difference in females and males $\mathrm{p}$ value $<0.0001$ such that the mean value of (MF-MB) in males was greater than in females.

Mean of (MF-MN) in females was $16.03 \mathrm{~mm} \pm 2.44$ while, in males was $15.76 \mathrm{~mm} \pm 3.38$. 
Mean of $(\mathrm{PB}-\mathrm{MF})$ in females was $12.04 \mathrm{~mm} \pm 1.85$ while, in males was $12.66 \mathrm{~mm} \pm 2.37$..

The PB-MF shows low significant difference in females and males as $(\mathrm{p}=0.01)$.

Mean of $(\mathrm{AB}-\mathrm{MF})$ in females was $16.83 \mathrm{~mm} \pm 2.58$ while, in males was $17.61 \mathrm{~mm} \pm 2.87$. 87 .

The AB-MF shows low significant difference in females and males as $(\mathrm{p}=0.024)$.

Table (2): Illustrating mean $\pm S D$ of $M F-M B, M F$ $M N, P B-M F$, and $A B-M F$ in right and left side.

\begin{tabular}{|c|c|c|c|}
\hline & $\begin{array}{c}\text { Right side } \\
\text { Mean } \pm \text { SD }\end{array}$ & $\begin{array}{c}\text { Left side } \\
\text { Mean } \pm \text { SD }\end{array}$ & P value \\
\hline MF-MB & $29.39 \pm 4.18$ & $29.04 \pm 4.58$ & 0.486 \\
\hline MF-MN & $15.81 \pm 2.73$ & $16.04 \pm 2.95$ & 0.489 \\
\hline PB-MF & $12.31 \pm 1.90$ & $12.25 \pm 2.27$ & 0.796 \\
\hline AB-MF & $16.90 \pm 2.53$ & $17.37 \pm 2.89$ & 0.138 \\
\hline
\end{tabular}

Table (2) shows parameters related to the exact location of mandibular foramen in right $\&$ left sides as follows:

Meanof(MF-MB)inrightsidewas 29.39mm \pm 4.18 while, in left side was $29.04 \mathrm{~mm} \pm 4.58$.

Meanof(MF-MB)inrightsidewas 15.81 $\mathrm{mm} \pm 2.73$ while, in left side was $16.04 \mathrm{~mm} \pm 2.95$.

Mean of (PB-MF) in right side was $12.31 \mathrm{~mm} \pm 1.90$ while, in left side was $12.25 \mathrm{~mm} \pm 2.27$.

Mean of(AB-MF)inrightside was $16.90 \mathrm{~mm} \pm 2.53$ while, in left side was $17.37 \mathrm{~mm} \pm 2.89$.

All parameters show no significant difference as $\mathrm{p}$ value $>0.05$.

\section{DISCUSSION}

Inferior alveolar nerve block is one of the most common nerve block technique used in dental practice. It is the most frequently used technique for local anesthesia when performing restorative and surgical procedures in the mandible. However, the approximate failure rate of this procedure has been reported to range from 20 to $25 \%{ }^{(11)}$. The success of the procedure mainly depends on placing the needle tip close to the mandibular foramen. Variations in the position of the mandibular foramen and the presence of accessory mandibular foramina are the main reasons accounting for the failure rates of this technique ${ }^{(12)}$.

The location of the Mandibular foramen is essential for mandibular surgeries like split sagittal osteotomy and esthetic surgeries for dentofacial deformities. Variations in the position of mandibular foramen and the presence of accessory mandibular foramina are the main reasons accounting for the failure rates of this technique ${ }^{(2)}$. During surgical procedures which involve the ramus of the mandible, it is important to be familiar with the incidence and the configuration of these foramina, since complications including unexpected bleeding, parathesia and traumatic neuroma are known to occur because of trauma to the accessory canals ${ }^{(8)}$.

The assessment of the MF variations is a key step in the correct execution of the inferior alveolar nerve block or in oral- maxillofacial surgery planning. Thus, knowledge about the anatomical variations in different populations is imperative for dental clinicians ${ }^{(12)}$. Many studies are carried out on different populations evaluating the anatomical position of MF on CBCT images in the vertical and horizontal dimensions of ramus. In 2016 MF was evaluated position in Indian population. Another study analyzed the MF location in Korean population. Another study was conducted on France patients. Most of studies carried out on Egyptian population focused on anatomical variations of mandibular canal and mental foramen, thus to compensate 
for this shortage in previous studies we aimed to assess position of mandibular foramen using CBCT in Egyptian population. ${ }^{(13-15)}$

This study evaluated the position of mandibular foramen in Egyptian population using CBCT. It is the most recent imaging technique in the maxillofacial imaging. The introduction of CBCT imaging has made a shift from a two - dimensional to a three - dimensional volumetric approach in maxillofacial imaging. From a radiological perspective, the main advantage of CBCT is its ability to acquire 3D reconstructions of the dentomaxillofacial region with high levels of detail. When compared with multislice CT $(\mathrm{MSCT})^{(9)}$.

3D technology has a huge number of advantages over technologies like traditional $\mathrm{x}$-ray with medical computed tomography. The main advantages of the CBCT in comparison with spiral computed tomography are the higher resolution, the significantly lower radiation burden and that artifacts, caused by metallic structures are much less disturbing. Cone beam computed tomography imaging has an incredible resolution, allowing for highly accurate imaging and measuring. This means these images can be used to pinpoint the exact location for a dental procedure ${ }^{(10)}$.

This descriptive and analytical study evaluated MF in panoramic based on CBCT images of adult patients. CBCT images retrieved from the outpatient clinic of the department of oral medicine, periodontology, diagnosis and oral radiology, faculty of dental medicine, boys, Cairo, Al-zahar universityoral \& maxillofacial radiology, El Minia university and other private radiology centers in different areas in the Egypt to make a survey for all Egyptian resides. The mandibular foramina in the right and left sides were evaluated on reconstructed panoramic images. All reconstructed panoramic images were evaluated according to sex and symmetry of both sides of the mandible. Each cone beam computed tomography (CBCT) image was evaluated by Blue Sky Bio software. This processing software is one of the software programs that is capable of analyzing CBCT images imported from different CBCT machines with different softwares. In 2018, a study evaluated CBCT images to determine the position of MF relative to the anterior and posterior borders of ramus, inferior border of the mandible and mandibular notch. Another studies conducted in 2015 and 2014 evaluated the position of mandibular foramen relative to these four references using reconstructed panorama based on CBCT images ${ }^{(16-18)}$.

The results of this study showed that, the mean distance from mandibular foramen to mandibular base (MF-MB) was $29.39 \mathrm{~mm}$ in the right side and $29.04 \mathrm{~mm}$ in the left side. These values were larger than those reported in another study in Iran. These values were $27.61 \mathrm{~mm}$ and $27.60 \mathrm{~mm}$ respectively. In this study, the mean distance from mandibular foramen to mandibular notch (MF-MN) in the right side was $15.81 \mathrm{~mm}$ and $16.04 \mathrm{~mm}$ in left side. These values were smaller than values obtained in a study done by in Iranian population. They were $17.40 \mathrm{~mm}$ in the right and $17.55 \mathrm{~mm}$ in the left side. In another study carried out in Indian population, this distance was $21.74 \mathrm{~mm}$ in the right and $21.92 \mathrm{~mm}$ in the left side $^{(16,18)}$.

The results showed that the mean distance from posterior border of the ramus to the mandibular foramen (PB-MF) was $12.31 \mathrm{~mm}$ in the right side and $12.25 \mathrm{~mm}$ in the left side. These values were close to those in the Indian population (around $12 \mathrm{~mm}$ ). while they were larger than values reported in a study done in Iran population (around $7 \mathrm{~mm}$ ) and smaller than values in Zimbabwean population (around 14mm) ${ }^{(12,16,19)}$.

In this study the mean distance from anterior border of the ramus to the mandibular foramen (ABMF) was $16.90 \mathrm{~mm}$ in the right side and $17.37 \mathrm{~mm}$ in the left side. These obtained values were close to those reported in Indian population. While these values were $17-18 \mathrm{~mm}$ in another study. However these values were smaller than those measured in Zimbabwean population (around $19 \mathrm{~mm}$ ) and larger than those reported in Brazilian subpopulation. 
(11.8mm). According to the findings in this study, no significant difference existed in the position of the mandibular foramen in the right and left sides, This finding was in agreement with the results of Shokri et al., since they did not find any significant difference in this respect between the right and left in Hamadan city ${ }^{(12,18-20)}$.

Results of this study showed that the mean distance from the mandibular foramen to mandibular base (MF-MB) was $28.32 \mathrm{~mm}$ in females and $30.59 \mathrm{~mm}$ in males. This means high significant difference between males and females as the distance was greater in males than in females $(p<0.0001)$. These findings were similar to a study conducted in Iran population by Sepideh Falah Kooshi et al. in $2018^{(16)}$. This study showed that the mean distance from mandibular foramen to mandibular notch (MF-MN) in females was $16.03 \mathrm{~mm}$ and in males was $15.76 \mathrm{~mm}$. This means that the distance from mandibular foramen to mandibular notch (MF-MN) was close in males to females. In contrast to a study conducted on a Chilean population showed that the distance from the mandibular foramen to the mandibular notch (MF-MN) in males $(24.35 \mathrm{~mm})$ was greater than in females $(22.0 \mathrm{~mm})^{(21)}$.

Obtained results showed that the mean distance from posterior border of ramus to mandibular foramen (PB-MF) in female was $12.04 \mathrm{~mm}$, and in males was $12.66 \mathrm{~mm}$. Our findings revealed low significant difference between males and females $(p=0.01)$. Lack of significant sexual differences of position of mandibular foramen was reported in Brazilian population $^{(22)}$. The results in this study showed that the distance from anterior border of ramus to mandibular foramen (AB-MF) was $16.83 \mathrm{~mm}$ in females and in males was $17.61 \mathrm{~mm}$. This means low significant difference between males and females $(\mathrm{p}=0.024)$. While a study conducted on Iran population that mean horizontal dimensions related to mandibular foramen (PB-MF) \& (AB-MF) in males was significantly greater than that in females ${ }^{(16)}$.

\section{CONCLUSIONS}

All parameters related to the position of mandibular foramen in vertical and horizontal dimensions of mandibular ramus (MF-MB, (MF-MN), (PB-MF), and (AB-MF) were symmetrical in the right and left sides.

The distance from mandibular foramen to mandibular base (MF-MB) was significantly different between males and females. It was larger in males than in females.

\section{REFERENCES}

1. Findik Y, Yildirim D, Baykul T. Three-dimensional anatomic analysis of the lingula and mandibular foramen: a cone beam computed tomography study. J Craniofac Surg. 2014: 25: 607-10.

2. DawJ, Paz D, Han H, Aitken E, Patel K. The mandibular foramen: an anatomic study and its relevance to the sagittal ramus osteotmy, J Craniofac Surg. 1999; 10:485-9.

3. Ghorai S, Pal M, Jana S. Distance of mandibular foramen from 3 rd molar tooth in dry adult mandibles of west Bengal population. Anat J Africa. 2016; 5: 640- 43.

4. Matveeva N, Popovska L, Evrosimovska B, Chadikovska E, Nikolovska J. Morphological alterations in the position of the mandibular foramen in dentate and edentate mandibles. Anat Sci Int. 2018; 93: 430-50.

5. Komar D, Lathrop S. Frequencies of morphological characteristics in two contemporary forensic collections; implications for identification, J Forensic Sci. 2006; 51: 974-8.

6. Neiva F, Gapsik R, Wang L. Morphometric analysis of implant -related anatomy in caucasian skulls , J periodontal, 2004;75:1061-7.

7. Bedrock D, Skigen A, Dolwick F. Retrieval of a broken needle in the pterygomandibular space. J Am Dent Assoc 1999 ; 130: 685-7.

8. Funibunda K, Matthews S. Relationship between accessory foramina and tumour spread in the lateral mandibular surface, J Anat. 1999; 195:185-90.

9. Angelopolos C, Scarfe C, Farman G. A comparsion of maxillofacial CBCT and medial CT, Atlas Oral Maxillofac Surg Clin North Am.2010; 20:1-17. 
10. Mah J, Yi L, Huang R, Choo H. Advanced applications of cone beam computed tomography in orthodontics. Semin Orthod. 2011;17: 57-71.

11. Goldberg S, Reader A, Drum M, Nusstein J, Beck B. Comparison of the anesthetic efficacy of the conventional inferior alveolar Gow-Gates and Vazirani-Akinosi techniques. J Endod.2008; 34:1306-11.

12. Thangavelu K, Kannan R, Kumar NS, Rethish E, Sabitha $S$, Sayeeganesh N. Significance of localization of mandibular foramen in an inferior alveolar nerve block. J Nat Sci Biol Med. 2012;3:156-60.

13. Khan I. An anatomical study and clinical correlations of mandibular Foramen in dry Adult human mandibles of North Indian Origin. Ann Int Med Dent Res. 2016; 4:161-64.

14. Kang H, Byan H, Kim H, Park H, Kim K. Threedimensional anatomic analysis of mandibular foramen with mandibular anatomic landmarks for inferior alveolar nerve block anesthesia. Oral Surg Oral Med Oral Pathol Oral Radiol. 2013; 115: 17-23.

15. Trost O, Salignon V, Cheynel N, Malka G, Trouilloud P. A. simple method to locate mandibular foramen: Preliminary radiological study. Surg Radiol Anat. 2010; 32:927-31.

16. Rezaei F, Imani M, Majidi S, Kooshki S. Three- dimensional position of mandibular foramen in a subpopulation residing in the west of Iran using panoramic based on cone beam computed tomography. J Res Med Dent Sci. 2018; 6: 449-58.

17. Aglarci O, Gungor E, Altunsoy M, Nur B, Ok E et al. Three dimensional analysis of mandibular foramen location: Cone beam computed tomography study. J Radiol, 2015; 4: 179-83.

18. Shokri A, Falah-Kooshki S, Poorolajal J, Karimi A, Ostovarrad F. Evaluation of the location of mandibular foramen as an anatomic landmark using CBCT images: a pioneering study in an Iranian population. Brazil Den Sci. 2014; $17: 74-81$.

19. Mbajiorgu F. A study of the position of the mandibular foramen in adult black Zimbabwean mandibles. The Central African Journal of Medicine. 2000;46:184-90.

20. da Silva Braga R, da Silva M, Galvanini A, Gomes P, Victorino R. Analysis of the mandibular foramen position and its implications to the inferior alveolar nerve block. Revista Odontolgica do Brasil Central. 2015: 23:67.

21. Alves N, Deana F. Morphometric study of mandibular foramen in macerated skulls to contribute to the development of sagittal split ramus osteotomy (SSRO) technique. Surg Radiol Anatomy. 2014; 36:839-45.

22. Bee M, Rabban M, Sethi H, Tran T, Baker C et al. variability of the mandibular foramen in African-American and Caucasian population of male and female skulls. Clin Ant. 2010; 12: 394-98. 


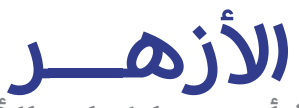 \\ مجلة أسيوط لطب الأسنان
}

النشر الرسمي لكلية طب الأسنان

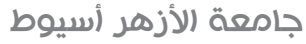

\title{
تقييم الاختلاف في مكان ثقبة الفك السفلي في المجتمع

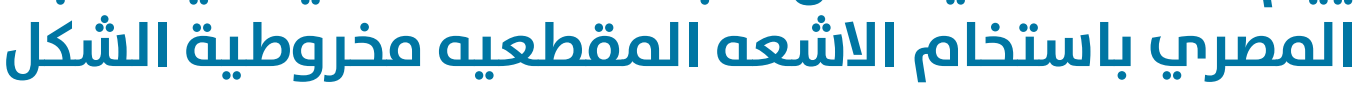

\author{
رنا هاشم1، احمد بكرى 2، فتحى ابوزيد33

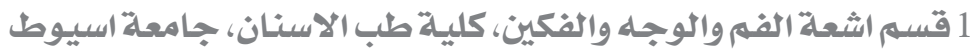 \\ 2 قسم اشعة الفم والوجه والفكين, كلية طب الاسنان ,جامعة المنيا \\ 3 قسم طب الفم وامراض اللثه والاشعه والتشخيص ,كلية طب الاسنان , جامعة الازهر, اسيوط , مصر \\ DRFATHEY@AZHAR.EDU.EG :البريد الاككترونى: *
}

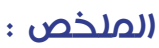

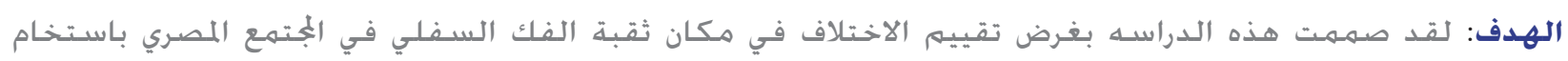

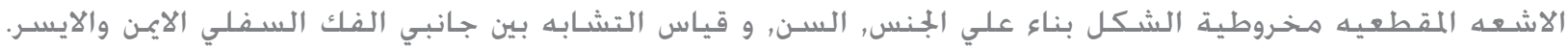

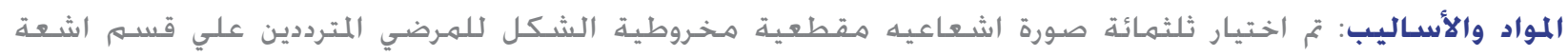

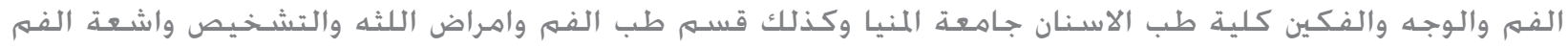

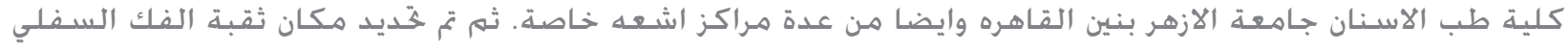

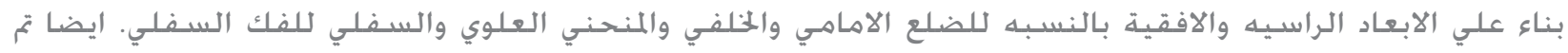

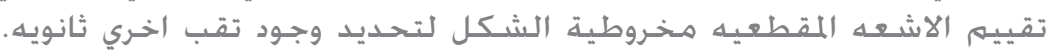

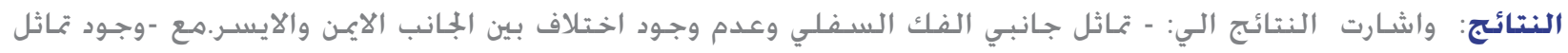

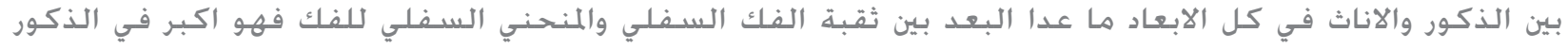

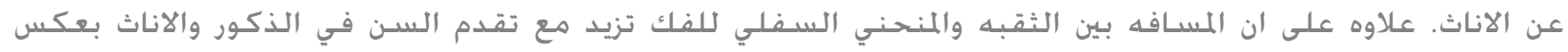

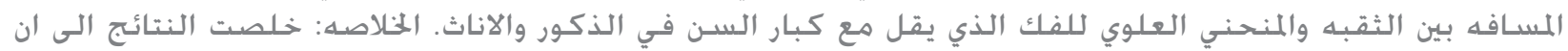

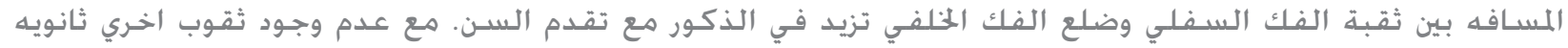

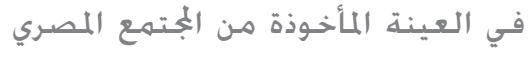

الكـلمـات المفتاحيه: ثقبـة الفك السفلى، الاشعهـ المقطعيه مخـروطية الشـكل، ضلع الفك الخلفى، المنحنى العلوى للفك، اشعهـ مقطعيه 